\title{
El "infoentretenimiento" en Internet. Un análisis del tratamiento político de José Luis Rodríguez Zapatero, Mariano Rajoy, Gaspar Llamazares y Rosa Díez en YouTube
}

\section{Political infotainment on the Internet. Analysis of the most viewed videos on YouTube of Jose Luis Rodríguez Zapatero, Mariano Rajoy, Gaspar Llamazares y Rosa Díez}

\author{
Salomé Berrocal Gonzalo. Universidad de Valladolid \\ Eva Campos Domínguez. Universidad de Valladolid \\ Marta Redondo García. Universidad de Valladolid
}

Recibido: 26-III-2012 - Aceptado: 2-VII-2012

Resumen:

Esta investigación se centra en el estudio del infoentretenimiento político, un género vinculado en su nacimiento a la televisión, pero que en los últimos años ha logrado tener presencia en el resto de los medios de comunicación, incluyendo la Red. El trabajo presenta una revisión del marco conceptual del infoentretenimiento político y de los principales estudios realizados en el ámbito internacional sobre el fenómeno y sus posibles influencias en la ciudadanía. Además, muestra cuál ha sido la evolución del infoentretenimiento político en el ámbito televisivo y cómo ha comenzado a manifestarse en Internet. Así, el estudio evidencia la presencia en la plataforma YouTube de un gran número de vídeos políticos que cumplen con las características del infoentretenimiento. De manera concreta, se presenta un análisis de los vídeos que aparecían destacados como aquellos más populares, por el número de reproducciones realizadas, cuando uno trataba de buscar información en YouTube de cuatro de los principales representantes de la política española en 2010: José Luis Rodríguez Zapatero, presidente del Gobierno en esa fecha, Mariano Rajoy, líder del Partido Popular, Rosa Díez, líder de Unión Progreso y Democracia y Gaspar Llamazares, líder de Izquierda Unida. Quizás habría que hablar del mensaje político y también de la investigación, un campo novedoso.

Palabras clave:

Infoentretenimiento, Comunicación Política, Internet, YouTube.

Abstract:

This research focuses in the study of political infotainment. Originally, this is a genre linked to television, but now it is present in other media as Internet. The paper reviews the conceptual framework of political infotainment and major studies in the international area on the phenomenon and its possible influence on citizens. It also shows what has been the evolution of political infotainment in television and how it has begun to appear on the Net. This article proves that many political videos of YouTube satisfy the characteristics of infotainment. Specifically, this paper shows the results of a analysis of the eighty most played videos in YouTube in 2010 of José Luis Rodríguez Zapatero, the prime minister of Spain, Mariano Rajoy, Popular Party leader, Rosa Díez, Unión Progreso y Democracia leader, and Gaspar Llamazares, Izquierda Unida leader.

Keywords:

Infotainment, Political Communication, Internet, YouTube. 


\section{El marco conceptual del infoentretenimiento político}

El origen del infoentretenimiento político se sitúa en los años 90 en aquellos países en los que existe una importante competencia en el sector audiovisual. El comienzo del fenómeno supone la presencia en los informativos televisivos tradicionales de noticias frívolas o superficiales que vienen a eliminar de la escaleta informativa noticias sobre asuntos serios, correspondientes a las áreas de política nacional e internacional. A esta situación se añade el nacimiento de programas que parodian la política y de emisiones en las que ésta se mezcla con las noticias relativas a sucesos o al mundo del corazón. En resumen, y siguiendo a Martínez Nicolás (2007), se configuran así productos mediáticos que sin ser propiamente periodísticos, informan y comentan los asuntos de actualidad política, social o económica, con el envoltorio de lo humorístico, jocoso, burlesco o de lo grotesco. Siguiendo distintos trabajos que abordan el tema (Baum, 2002; Blumler, Kavanagh, 1999; Brants, 1998; Delli Carpini, Williams, 2001; Holtz-Bacha, Norris, 2001; García Avilés, 2007; Prado, 2003; Schudson, 1999, entre otros), la tendencia del infoentretenimiento televisivo está presente en la mayoría de las democracias occidentales, manifestándose como un sustitutivo de la información pura, que ahora incorpora sentimientos personales, tintes dramáticos o ingredientes cómicos, hasta el punto que algunos investigadores como Sampedro llegan a preguntarse "¿Qué representa mejor la visión popular de la política, un telediario clásico o las parodias radiofónicas y las Noticias del Guiñol?” (2000: 39-40).

En el caso concreto de la información política, el infoentretenimiento se detecta en géneros tan variados como los informativos, los programas de entrevistas, los concursos, los talk-shows, los programas de parodia política o, incluso, en algunas series o películas en las que intervienen de manera esporádica los líderes políticos ${ }^{1}$.

En nuestro país, el primer estudio centrado en el análisis de programas de infoentretenimiento político televisivo se realiza en 2001, dentro de un proyecto de investigación ${ }^{2}$ destinado a conocer el desarrollo de la precampaña y campaña electoral del año 2000, en las cadenas de televisión de difusión nacional (Berrocal et al., 2001). En esa fecha son analizados los siguientes programas: Los Guiñoles de Canal +, El Informal de Tele 5 y Caiga quien Caiga, programa que también se emitía en Tele 5. Entre los resultados destacó el alto grado de politización de este tipo de programas, ya que en la precampaña dedicaron el $40 \%$ de su tiempo de emisión a noticias políticas y en la campaña electoral el porcentaje se situó en un $60 \%$ de tiempo de emisión dedicado a las informaciones políticas, con un tratamiento que se alejaba de la seriedad de los informativos tradicionales y que planteaba un enfoque de la política desde el humor, la sátira o el entretenimiento, pese a estar en campaña electoral.

http://www.xavierpeytibi.com/2010/11/25/los-cameos-politicos/, consultado el 21 de marzo de 2012.

2 Proyecto de investigación: “La influencia de la televisión en las elecciones legislativas de 2000", financiado por la Universidad San Pablo-CEU. Salomé Berrocal (Investigadora Principal del Proyecto), Leopoldo Abad, Elena Cebrián y Elena Pedreira (Investigadores del Proyecto). 
Esta investigación es paralela a los trabajos que se inician en otros países de Europa (Brants, 1998; Brants, Neijen, 1998), de Asia (Srirk, 2007), del mundo árabe (Bahry, 2001; Linch, 2004a, 2004b) y especialmente de Estados Unidos (Baum, 2003a, 2003b, 2005, 2006; Hollander, 2005; Moy, Xenos, Hess, 2006; Patterson, 2000), al producirse en el panorama internacional un fenómeno común: la proliferación de programas que realizan entretenimiento y que van a incluir la política entre sus contenidos.

Los trabajos reseñados abordan desde diferentes metodologías el tipo de presencia del político en estos programas, cuál es su discurso y cuál la posible influencia en la ciudadanía o, incluso, en la decisión de voto, en el caso de realizarse durante una campaña electoral. Los teóricos no se ponen de acuerdo en sus efectos. Hay quienes defienden como Baum (2002, 2003a, 2003b, 2005, 2006) o, más recientemente, Taniguchi (2011) que este tipo de presencia del político en programas de entretenimiento o en noticias frívolas o superficiales tiene una influencia positiva en aquellos electores que tienen un bajo conocimiento de la política. Mientras que hay autores en una posición diferente como Prior $(2003,2005,2007)$ que afirman que la influencia es negativa por informar de cuestiones anecdóticas al telespectador. De acuerdo con esta segunda opinión se manifiesta Blumler (1992) que, refiriéndose al fenómeno del infoentretenimiento, señala que hay una degradación de la política producida por varios factores: 1) la importancia de las percepciones de la política y de sus protagonistas en detrimento de los hechos, 2) la presentación de la política como un juego, 3) la disminución de espacio en los medios de comunicación para informar de la política con seriedad. Además, Blumler añade que existen signos sobre cómo los medios de comunicación promueven la proliferación de mensajes negativos sobre los actores políticos y sus decisiones, produciendo un incremento del cinismo y una debilitación de la comunicación política.

De ahí, que si se tuviera que establecer una clasificación de las líneas de estudio en las que se ha venido trabajando en los últimos años en el panorama internacional sobre el infoentretenimiento político en televisión, se podrían mencionar tres tipos de investigación: 1) el análisis conceptual del infoentretenimiento político, 2) el estudio de la presencia política en programas de info-shows concretos y 3) los trabajos destinados a conocer las consecuencias electorales de la presencia de los políticos o de la actualidad política en determinado tipo de programas de televisión.

En el caso español, los estudios acerca de esta tendencia en televisión son aún insuficientes. En el apartado conceptual destacan los trabajos de Berrocal (2003), Carpio (2009) o Valhondo (2011). En el marco del análisis sobre la presencia del político en programas concretos de infoentretenimiento en televisión, o en informativos, se amplía pero de manera aún escasa el número de estudios (Berrocal et al., 2003; García Avilés, 2007; Berrocal, Cebrián, 2009; Arroyo, 2008; Ferré y Gayà, 2009), mientras que en el apartado de las posibles influencias en la ciudadanía son muy pocos los autores que desarrollan esta línea de trabajo (Berrocal, 2003; Ferré y Gayà, 2009; Moreno del Río, 2010). Este panorama resulta, pues, insuficiente, dada la relevancia del tema, más aún si se compara con la literatura desarrollada, particularmente, en el ámbito anglosajón. 
En cuanto a la presencia del infoentretenimiento político en la Red es un asunto novedoso, con escasos trabajos, ya no solo en el panorama nacional sino también en el internacional. Algunos de los trabajos realizados en España (Berrocal y Campos, 2012) tienen que ver con el análisis en YouTube del infoentretenimiento en vídeos sobre políticos españoles y extranjeros ; mientras que en el apartado internacional, son escasos los trabajos localizados y los estudios también coinciden en centrarse en la red social YouTube (Tyron, 2008; Towner y Dulio, 2011).

\section{El infoentretenimiento político en España: su expansión desde la televisión al resto de los medios de comunicación}

Como ya se ha señalado, el infoentretenimiento político tiene sus orígenes en la televisión y en la importante competencia audiovisual que se vive en los años 90, una situación que provoca la búsqueda de la audiencia con un nuevo tratamiento informativo en el apartado de la política, más vinculado al entretenimiento que a la información, a la búsqueda de la anécdota política que a la seriedad que requiere el tratamiento informativo de la actualidad. Un fenómeno que no sólo se refleja en los informativos, sino que alcanza a nuevos programas que se crean en televisión relacionados de forma directa con la parodia política o a programas magazines que incluyen la política junto al resto de sus contenidos vinculados al entretenimiento del espectador.

El elenco de programas televisivos que, en la actualidad, se incluyen dentro de este género es numeroso, aunque cabría hablar de tres formatos (Berrocal y Cebrián, 2009), que acogen a un gran número de ellos: 1) los programas informativos “espectacularizados", 2) los magazines o "programas contenedores" y 3) los programas de parodia informativa o infoshow.

El primer tipo de formato, los programas informativos "espectacularizados", reúnen tanto a programas informativos diarios que incluyen un alto porcentaje de informaciones destinadas a despertar emociones en el espectador, como aquellos programas que contribuyen a descontextualizar la noticia o información que, en un principio, sería considerada como seria $^{3}$.

El segundo tipo de formato, los magazines o programas “contenedores", tienen una importante presencia en las parrillas de la programación televisiva y en ellos cabe desde la información seria hasta la más banal, programas en los que no hay una separación clara entre información y entretenimiento ${ }^{4}$.

El tercer tipo de formato, los infoshow son programas de entretenimiento, parodia o humor político claramente orientados a conseguir la diversión del espectador. De hecho, cualquier información es susceptible de convertirse en un espectáculo por el tratamiento que le concede este tipo de programas. Los programas infoshow o de parodia política son

3 Ejemplo de ello serían en nuestro país programas como: 59 segundos o Tengo una pregunta para usted de TVE.

4 Ejemplo de ello serían en nuestro país programas como: La Noria o El Programa de Ana Rosa, de Tele 5. 
un fenómeno internacional ${ }^{5}$. En la mayoría de los países con democracias arraigadas triunfa este tipo de formato, que suele alcanzar una importante audiencia.

En el caso español, el desembarco de los formatos de infoentretenimiento político lo inició Canal +, en 1995, con sus Guiñoles. Tras la aceptación recibida por Los Guiñoles, la cadena Tele 5 puso en marcha otros dos programas que inauguraron diferentes facetas del infoentretenimiento político: Caiga Quien Caiga-la adaptación de un formato argentino en 1996- y El Informal en 1998. En la actualidad, aunque estos programas han desaparecido, solo se emite en alguna temporada Caiga Quien Caiga en la cadena televisiva La Sexta, las parrillas de los diferentes canales de televisión en España han incorporado nuevos programas que gozan de las características esbozadas en el concepto de infoentretenimiento. Así, en la fecha de la investigación (abril de 2010) La Primera de TVE emitía 59 Segundos, Antena 3 Espejo Público, Tele 5 El Programa de Ana Rosa y La Noria, La Sexta Buenafuente, El Intermedio y Salvados. Una programación amplia dedicada al infoentretenimiento que podría incrementarse con el tratamiento que algunos informativos de la televisión en España otorgan a la información política.

Una situación similar a la televisiva se ha vivido en los últimos años tanto en la radio como en la prensa española, ya que el prisma del infoentretenimiento puede ser el elegido por muchos periódicos y cadenas de radio para tratar determinadas informaciones políticas e, incluso, para seleccionar qué cuentan de la realidad política nacional e internacional. En prensa: el predominio de la imagen en detrimento del texto, la personalización de la política en las informaciones, la introducción de la anécdota ocurrida a un líder político, el relato de las características personales del candidato e, incluso, de sus relaciones sentimentales tienen cabida en las páginas de los diarios incluso, en ocasiones, por delante de las informaciones más serias de política nacional o internacional ${ }^{6}$.

En cuanto a la programación radiofónica también ha experimentado en los últimos diez años cambios que tienen que ver con el incremento de tertulias radiofónicas en todas las cadenas de radio y a casi todas las horas, con un tratamiento, en ocasiones, frívolo y superficial de los acontecimientos, el nacimiento de programas contenedor como los televisivos, donde caben las informaciones serias junto a las puramente anecdóticas o referidas a asuntos del corazón y la importante presencia de imitaciones de los políticos?

5 Ejemplo de ello serían en nuestro país programas como: El Intermedio de La Sexta. En USA son ejemplos de programas de infoshow: The Daily Show, The Colbert Report, The Late Show with David Letterman o The Tonight Show with Jay Leno.

6 Un ejemplo de ello puede ser el tratamiento informativo concedido por los diarios españoles a la primera visita del presidente francés Nicolas Sarkozy a España, el 27 de abril de 2009. Así, el diario El País, el 28 de abril, arrancó en su primera página con una fotografía de la princesa Letizia y la primera dama francesa, Carla Bruni, de espaldas y subiendo una escalera en estudiada simetría, más propia de la prensa rosa que de la prensa de calidad, y ocupándose solamente en el texto del presidente Sarkozy y los objetivos de su visita. El Mundo tituló el 27 de abril "Bruni eclipsa a Sarkozy" y el periódico ABC: "Doña Letizia gana a Carla Bruni en el duelo de la elegancia”, el 29 de abril.

7 El imitador Carlos Latre es un ejemplo de ello, ha participado con sus imitaciones, incluyendo las de los políticos en programas de te- 
La explicación a esta expansión del infoentretenimiento informativo a otros medios de comunicación, como prensa y radio, puede tener que ver con el afán de seguir los pasos de la televisión. "Tal vez, atraídos por el tratamiento visual, personalista y emocional que ya se les ha dado en televisión, y pensando que, también, ellos lograrán atraer al público hasta sus informaciones si comparten el mismo enfoque, la prensa y la radio han iniciado, en los últimos años, su aproximación al género del “infoentretenimiento” (Cebrián y Berrocal, 2009).

En cuanto al desplazamiento del fenómeno a la Red podría tener que ver, como señala Díaz Arias, con un reflejo social, cuando afirma que en cualquier web siempre las noticias más visitadas pertenecen a la categoría del infoentretenimiento y que la sociedad actual no quiere que el espejo le devuelva una imagen de sus miserias sino que desea una imagen más amable (2007).

\section{El infoentretenimiento político en Internet}

Internet está considerada como una fuente de noticias donde los usuarios buscan y comparten información de manera constante. Una de las plataformas más destacadas es YouTube, que se autodefine como "la comunidad de vídeos online más popular del mundo, permitiendo a millones de usuarios descubrir, visualizar y compartir sus vídeos originales" (YouTube 2010). Esta página fundada en 2005, proporciona un foro donde sus usuarios pueden conectarse, informarse e inspirar a otras personas de todo el mundo. Cada minuto se suben 20 horas de contenido y cada día se ven 1.000 millones de vídeos en todo el mundo ${ }^{8}$. YouTube lanzó su versión española en 2006 y cuenta, en la actualidad, en nuestro país con 14 millones de usuarios.

YouTube permite a los ciudadanos participar de la política creando contenidos al mismo tiempo que concede a los políticos la posibilidad de llegar con sus vídeos hasta los ciudadanos de una manera directa.

Un estudio realizado en 2008 sobre las elecciones en Estados Unidos y el uso de YouTube (Hanson, Haridakis y Sharma, 2011) sugiere que los electores acudieron a este medio por las mismas razones que acudían en el pasado a los medios tradicionales. Así, la investigación señala que los cinco géneros más consumidos en YouTube, durante la campaña electoral, relacionados con la información política fueron: las noticias de los informativos televisivos, las informaciones aparecidas en programas de parodia o sátira política, los anuncios políticos, los comentarios directos a cámara de los candidatos y los vídeos creados por usuarios activos en la Red. Tres de las cinco categorías reflejan que los contenidos proceden de la televisión tradicional (noticias de informativos, programas de humor o parodia política y anuncios políticos). Según afirman los encuestados en este trabajo, el principal motivo para utilizar YouTube tiene que ver con la búsqueda del entreteni-

levisión como Crónicas Marcianas, Crackòvia o Polònia para recalar en el programa radiofónico Herrera en la Onda, de Onda Cero, donde colabora desde hace varios años.

8 “Cinco años que parecen 50", El País, 21/03/2010, p. 66. 
miento, seguida de otras razones como la búsqueda de información en general. Los resultados del trabajo apuntan que YouTube tiene su lugar en la comunicación política y, en particular, parece tenerlo el infoentretenimiento político.

Como señala Campos (2011), esta plataforma es una de las herramientas que ha adquirido un mayor número de adeptos que desean tanto difundir contenidos humorísticos como informativos. De esta manera, cabe hablar de que el éxito del género del infoentretenimiento político ha traspasado la televisión para filtrarse en la Red. Vídeos serios, puramente informativos, del ámbito político se funden en Youtube con los cortes de programas televisivos de infoentretenimiento que los usuarios cuelgan o, incluso, con espacios de parodia política de nueva creación para el escaparate virtual.

\section{Resultados de un análisis empírico del tratamiento político de vídeos en YouTube de José Luis Rodríguez Zapatero, Mariano Rajoy, Rosa Díez y Gaspar Llamazares}

\subsection{Introducción metodológica}

Este estudio pretende conocer si el fenómeno del infoentretenimiento televisivo se ha transferido a la Red. Para ello, se analizan qué tipo de vídeos son los más vistos por los usuarios en la plataforma de YouTube sobre José Luis Rodríguez Zapatero -candidato líder del PSOE y presidente del Gobierno en el periodo de análisis-, Mariano Rajoy -entonces candidato líder del Partido Popular y líder de la oposición-, Gaspar Llamazares que era portavoz parlamentario de Izquierda Unida y Rosa Díez -candidata de Unión Progreso y Democracia-.

La investigación parte, como hipótesis principal, de que los vídeos más vistos en YouTube sobre los políticos referidos pertenecen al género del infoentretenimiento. Al margen de ello, en este análisis se trata de verificar otras cuestiones secundarias como: 1) Si los líderes políticos más populares, atendiendo a su mayor representación mediática, cuentan con más vídeos vinculados al infoentretenimiento que aquellos líderes que tienen menor presencia en los medios de comunicación y, en particular en la televisión. 2) Si la mayor parte de los vídeos vinculados al infoentretenimiento y más populares, por número de reproducciones, están realizados por internautas creativos que utilizan como materia base imágenes de programas de televisión. 3) Si el perfil de quienes realizan comentarios es el de más hombres que mujeres y más jóvenes que población adulta. 4) Si la personalización política se refleja en la selección de los internautas a la hora de consumir infoentretenimiento en la Red, y, por tanto, los vídeos más populares tienen como protagonista al líder del partido y no al partido político en sí. 5) Si en los vídeos más populares, vinculados al infoentretenimiento existe, mayoritariamente, un sesgo negativo hacia el líder político que se muestra.

Para la selección de los vídeos se aplicaron los siguientes criterios de búsqueda en YouTube: además del nombre del candidato como palabra clave -Zapatero, Rajoy, Llamazares y Rosa Díez, según cada caso- se precisó el tipo de resultado de 
la búsqueda a vídeos ordenados por volumen de reproducciones, que hubieran sido subidos a la plataforma en cualquier momento y, finalmente, para los criterios de características, duración y categorías se seleccionó la opción de filtro "todos". El análisis se restringió a los veinte primeros vídeos ${ }^{9}$ que aparecían con estos criterios para cada candidato -eliminando, únicamente en el caso de Zapatero, dos vídeos cuyo contenido no estaba relacionado con el candidato del PSOE-. La búsqueda se realizó el mismo día para los cuatro políticos: 6 de abril de 2010.

Este estudio exploratorio se basa en un análisis de contenido cuantitativo y descriptivo. Para la recogida de información se optó por las listas de comprobación o checklist (del Rincón et al., 1995). La plantilla se estructuró en 16 variables organizada según las siguientes preguntas de investigación: ¿Cuál es el tema principal del vídeo?, ¿icuál es la fecha de subida del vídeo a Youtube?, ¿ cuándo registró el vídeo el último comentario de los usuarios?, ¿qué tipo de vídeo es?, ¿quién es el autor del vídeo?, ¿ipor quién ha sido subido a Youtube el vídeo?, ¿el vídeo fue creado específicamente para Internet o, por el contenido, pertenece a un programa de televisión, por ejemplo, y es reproducido en Youtube?, ¿ cuántos comentarios de usuario tiene el vídeo?, ¿̇en qué tipo de usuario es popular el vídeo?, ¿quién es el protagonista del vídeo?, ¿en qué actitud se le muestra?, ¿qué sesgo tiene el vídeo?, ¿el objetivo es el partido?, ¿ es el líder y su acción política?, ¿̇o es el líder en su apartado personal? La ficha de análisis ha sido diseñada a partir de variables independientes y dependientes, con opciones de repuesta múltiple o dicotómica. La plantilla fue aplicada por dos codificadoras, con un índice de concordancia intraobservadoras sustancial $(\mathrm{K}=0,61)$.

\subsection{Los vídeos más vistos en YouTube son mayoritariamente de humor}

El vídeo más visto en YouTube de José Luis Rodríguez Zapatero suma, a 6 de abril de 2010, un total de 2.471 .464 reproducciones, y el de Mariano Rajoy, 852.328. Lejos se sitúa el vídeo más visto de Rosa Díez, con 249.915 reproducciones, y el de Gaspar Llamazares, que sólo acumula 82.469 (treinta veces menos que el vídeo más reproducido del entonces presidente del gobierno).

El vídeo que ocupa el puesto veinteavo en el número de reproducciones sobre el líder del PSOE contabiliza 185.010 reproducciones, y el del líder del PP, 86.294. También en este caso, Gaspar Llamazares y Rosa Díez se encuentran muy por debajo de esas cifras. El vídeo que acumula menos reproducciones de Rosa Díez tiene 19.023, mientras que el vídeo menos visto de Llamazares suma 11.002.

En cuanto a la tipología de los vídeos, se ha utilizado la siguiente plantilla clasificatoria para establecer si se tratan de vídeos de humor, informativos, institucionales o de crítica:

9 Los veinte vídeos corresponde al número de ellos que aparecían en la portada de Youtube, una vez aplicados los criterios de búsqueda. 
Tabla I. Descripción de categorías temáticas de los vídeos

\begin{tabular}{|c|c|c|c|}
\hline Humor & Informativo & Institucional & Crítica \\
\hline $\begin{array}{l}\text { Categoría relacionada con el } \\
\text { humorismo, resaltando el } \\
\text { lado risueño, alegre y lúdico } \\
\text { del vídeo. }\end{array}$ & $\begin{array}{l}\text { Categoría que agrupa a los } \\
\text { vídeos que dan cuenta de } \\
\text { algún hecho, noticia o cir- } \\
\text { cunstancia objetiva. }\end{array}$ & $\begin{array}{l}\text { Categoría reservada a vídeos } \\
\text { distribuidos por institucio- } \\
\text { nes políticas. En esta } \\
\text { categoría, en el caso de de- } \\
\text { tectarse algún elemento que } \\
\text { convierta el vídeo en info- } \\
\text { tainment será señalado. En } \\
\text { el apartado institucional se } \\
\text { engloban las acciones dis- } \\
\text { cursivas, así como las } \\
\text { acciones de propaganda co- } \\
\text { munes, que suelen utilizar } \\
\text { los partidos políticos para } \\
\text { dirigirse a un potencial elec- } \\
\text { torado internauta. }\end{array}$ & $\begin{array}{l}\text { En esta categoría se agrupan } \\
\text { los vídeos cuya carga princi- } \\
\text { pal es la expresión de un } \\
\text { juicio en el que se reprueba } \\
\text { una acción política del pro- } \\
\text { tagonista político o de su } \\
\text { partido. El objetivo no es } \\
\text { otro que el de reprochar, y } \\
\text { esta acción de crítica supera } \\
\text { los elementos correspon- } \\
\text { dientes al infotainment, en } \\
\text { el caso de que los hubiera en } \\
\text { el vídeo analizado. }\end{array}$ \\
\hline
\end{tabular}

Fuente: Elaboración propia

Atendiendo a la clasificación indicada en la Tabla I, la investigación muestra que más de la mitad de los 40 vídeos más vistos en YouTube, en la misma fecha, del presidente y del líder de la oposición son vídeos de humor (Tabla II). Mariano Rajoy es, por su parte, el candidato que acumula un mayor número de vídeos de humor (13 de los 20) frente al líder del PSOE ${ }^{10}$. Sin embargo, los líderes de partidos menos mayoritarios, Gaspar Llamazares y Rosa Díez, invierten esa tendencia: sus vídeos más vistos en el sitio web son en su mayoría de carácter informativo (21 de 40). En el caso de Llamazares, las cifras entre ambos tipos están más equilibradas, sin embargo la candidata de UPyD no registra ningún vídeo humorístico y 13 de sus 20 vídeos más reproducidos son informativos.

10 Sirvan como ejemplos los vídeos titulados: "Rajoy a lo Michael Jackson" [http://www.youtube.com/watch?v=DGZab10Vrzc, última consulta: 30 abril de 2010], "Mariano Rajoy y sus pitufos” [http://www.youtube.com/watch?v=MHA-Y8lHvVo , última consulta: 30 abril de 2010] o "La RAI se ríe de Zapatero" (simulando el hipotético parecido del Presidente del Gobierno con el cómico británico Mrs. Been [http://www.youtube.com/watch?v=E_CY_oN1YTw, , última consulta: 30 abril de 2010] o “Zapatero dice 'para follar' en vez de 'para apoyar”" [http://www.youtube.com/watch?v=Mj6MjaJ1H-Q , última consulta: 30 abril de 2010]. 
El desequilibrio en la cantidad de vídeos informativos entre los líderes de los dos principales partidos españoles y los líderes minoritarios se puede explicar por la inferior representación mediática de que disfrutan estos últimos y que provoca que sean más activos en buscar fórmulas alternativas de hacer llegar su mensaje a los ciudadanos, como puede ser colgar vídeos en YouTube o difundir entre sus simpatizantes la dirección de vídeos donde se puede escuchar el mensaje del líder. A este respecto, es significativo adelantar aquí que 9 de los 40 vídeos de los dos líderes fueron subidos a la plataforma por el propio partido, por tanto se tratan de vídeos de contenido institucional.

A los vídeos de humor e informativos, le siguen, por este orden, los de crítica, en cuya categoría José Luis Rodríguez Zapatero registra un mayor número $(9 \text { de los } 15)^{11}$, y los institucionales (9).

Tabla II. Tipo de vídeo detallado por líder político

\begin{tabular}{|c|c|c|c|c|c|}
\hline & José Luis Zapatero & Mariano Rajoy & Gaspar Llamazares & Rosa Díez & Total de vídeos \\
\hline Humor & 8 & 13 & 6 & 0 & 27 \\
\hline Informativo & 3 & 2 & 8 & 13 & 26 \\
\hline Institucional & 0 & 0 & 3 & 6 & 9 \\
\hline Crítica & 9 & 4 & 2 & 0 & 15 \\
\hline Otros & 0 & 1 & 1 & 1 & 3 \\
\hline Total & 20 & 20 & 20 & 20 & 80 \\
\hline
\end{tabular}

Fuente: Elaboración propia a partir de los vídeos de YouTube reproducidos el 6 de abril de 2010

El episodio entre el Rey de España, el presidente del Gobierno español, José Luis Rodríguez Zapatero y el presidente de Venezuela, Hugo Chávez, en la Cumbre Iberoamericana de 2007, "la niña de Rajoy ${ }^{12 ”}$ y el nacionalismo catalán ${ }^{13}$ inspiran, en total, 6 de los 27 vídeos de humor. El resto de vídeos de humor tiene una temática diversa: "las hijas de Zapatero", el do-

11 Por ejemplo, criticando la falta del dominio del presidente del idioma anglosajón. En esta línea, el vídeo titulado "Zapatero hace el ridículo (Censurado en TV)" [http://www.youtube.com/watch?v=R6GQ-5-Kb7Q, última consulta: 30 abril de 2010] o "Zapatero hablando inglés" [http://www.youtube.com/watch?v=ZBuKZLyqJ8g, última consulta: 30 abril de 2010].

12 El vídeo titulado "Encontramos a la niña de Rajoy”, simulando a la serie de dibujos animados Heidi, es muestra de ello [http://www.youtube.com/watch?v=VGiBf-f-1jo, última consulta: 30 abril de 2010].

13 Para ilustrar, véase el vídeo titulado "Rajoy presenta 'Somos España” del programa de la televisión catalana TV3, Polónia [http://www.youtube.com/watch?v=--WAmQCeRdQ, última consulta: 30 abril de 2010]. 
minio del idioma inglés del presidente del Gobierno, los supuestos problemas internos del Partido Popular, o la falta de protagonismo político de Izquierda Unida, entre otros ${ }^{14}$.

Los vídeos informativos más vistos se centran en el episodio de la Cumbre Iberoamericana, en el accidente de helicóptero que Aguirre y Rajoy tuvieron en diciembre de 2005, y en la opinión que manifestó el líder del PP, en octubre de 2007, sobre el cambio climático citando como fuente a un primo suyo Catedrático de Física Teórica de la Universidad de Sevilla . En el caso de los líderes minoritarios, los vídeos informativos más vistos son intervenciones polémicas de ambos líderes en programas informativos espectacularizados como Tengo una pregunta para usted (TVE) en el caso de Llamazares y Madrid Opina (TeleMadrid) en el caso de Rosa Díez, en cuyo caso la disputa que mantuvo con la periodista y contertulia María Antonia Iglesias es, con diferencia, su vídeo más seguido.

Los vídeos informativos más vistos en YouTube se refieren a anécdotas, broncas y altercados. Se trata de una circunstancia en consonancia con el fenómeno aquí analizado, el infoentretenimiento, que frente a los asuntos de importancia objetiva prioriza temas menores pero espectaculares que despiertan una automática curiosidad por parte del público. Asuntos que, sin vinculación con la explicación razonada de la realidad o el debate de ideas, se quedan en el suceso llamativo que se sale de la norma. A este respecto es revelador el caso de Rosa Díez; seis de sus vídeos informativos más vistos recogen diversas escenas de insultos o intentos de agresión sufridos por la líder de UPyD ${ }^{16}$.

Por lo que se refiere a los vídeos de crítica, además de los temas vinculados con el dominio de inglés de Zapatero y "La niña de Rajoy", la mayoría se centran en temas como los atentados del 11-M, los pisos de 30 metros, el matrimonio gay, el canon digital, la asignatura de Educación para la Ciudadanía, el empleo y la economía o ETA. Generalmente, con crítica dirigida al Presidente del Gobierno ${ }^{17}$.

14 Véanse los vídeos titulados: “Las hijas de ZP, en NY” [http://www.youtube.com/watch?v=j3zJM_JgrxQ, última consulta: 30 abril de 2010] o "Zapatero y Rajoy, pasiones ocultas" [http://www.youtube.com/watch?v=xjpyC8vymqQ, última consulta: 30 abril de 2010], "Yo rompo con Zapatero, no más adoctrinamiento" [http://www.youtube.com/watch?v=cvrhk_7qRlM, última consulta: 30 abril de 2010] o, entre otros, “¡Rompe con Zapatero! ¡Rompe con los titiriteros!” [http://www.youtube.com/watch?v=oeDGXsdZZoI, última consulta: 30 abril de 2010] o "El chiki-chiki del voto útil. Lo cantan Llamazares y Rovira" [http://www.youtube.com/watch? $\mathrm{v}=04 \mathrm{BjHCMeObg}$, última consulta 30 de abril de 2020].

15 Es el caso del vídeo titulado "El Rey manda callar a Hugo Chávez" [http://www.youtube.com/watch?v=utSKLe05p1s, última consulta: 30 abril de 2010], 2007 en la Cumbre Iberoamericana de 2007, o el accidente que Esperanza Aguirre, presidenta de la Comunidad de Madrid, y Mariano Rajoy tuvieron en helicóptero, el 2 de diciembre de 2005 [http://www.youtube.com/watch?v=Y1zTnYYKOtY, última consulta: 30 abril de 2010].

16 Es el caso de los vídeos "La extrema izquierda revienta un acto de Rosa Díez" [http://www.youtube.com/watch?v=tDsqia9kyiE, última consulta: 30 abril de 2010], "Intento de agresión a Rosa Díez en Barcelona" [http://www.youtube.com/watch?v=0BhmUBo Xz0, última consulta: 30 abril de 2010] o "Radicales intentan boicotear un acto de Rosa Díez" [http://www.youtube.com/watch?v=0mZ1qDdTy6A, última consulta: 30 abril de 2010].

17 Como ejemplos figuran los siguientes vídeos: "Adiós Zapatero traga sapo" sobre las explosiones de los trenes en Atocha 
Respecto a los vídeos institucionales, suman 9 vídeos, lo que supone un 11,25\% del total.

Tabla III. Matices relativos al contenido de los vídeos analizados

\begin{tabular}{|c|c|c|c|c|}
\hline \multicolumn{5}{|c|}{ Número de vídeos en los que el protagonista es: } \\
\hline El líder político = 57 & El partido $=5$ & Terceras personas $=18$ & Total $=80$ & \\
\hline \multicolumn{5}{|c|}{ Número de vídeos en los que se muestra al líder político en actitud: } \\
\hline Cómica = 17 & Neutra $=51$ & Favorable $=8$ & Desfavorable $=4$ & Total $=80$ \\
\hline \multicolumn{5}{|c|}{ Número de vídeos en los que el objetivo es: } \\
\hline El partido $=14$ & $\begin{array}{l}\text { El líder y su acción } \\
\text { política = } 54\end{array}$ & $\begin{array}{l}\text { Líder en su faceta } \\
\text { personal = } 8\end{array}$ & Total $=76$ & \\
\hline \multicolumn{5}{|c|}{ Número de vídeos en los que el sesgo del vídeo es: } \\
\hline Positivo $=13$ & Neutro $=38$ & Negativo $=29$ & Total $=80$ & \\
\hline
\end{tabular}

Fuente: Elaboración propia a partir de los vídeos de YouTube reproducidos el 6 de abril de 2010

En la mayoría de estos vídeos (Tabla III), el protagonista es el líder político (en 57 de los 80 vídeos, un 71,2\%), aunque en ocasiones también figuran como protagonistas terceras personas -por ejemplo, el Rey de España y el Presidente de Venezuela- o el propio partido político.

Los cuatro políticos, Zapatero, Rajoy, Llamazares y Díez aparecen generalmente, en estos vídeos, en una actitud neutra (en 51 vídeos, 63,7\% de los vídeos) o cómica (en 17,21,2\% de los vídeos). Rajoy aparece en más vídeos en actitud cómica que Zapatero, mientras que éste se encuentra más veces en actitud desfavorable que el primero. Si atendemos al sesgo del vídeo, los líderes de los dos principales partidos figuran en igual número de vídeos (11) con sesgo negativo, seguidos de Llamazares que acumula 7 vídeos de este tipo. Análisis aparte merece la candidata de UPyD que en sus 20 vídeos más vistos no registra ninguno con sesgo negativo, siendo 19 neutros y uno positivo.

En 8 de los 80 vídeos analizados el objetivo no es ni el líder y su acción política, ni el partido político, sino la dimensión personal del candidato. José Luis Rodríguez Zapatero es, en este caso, el político que acumula un mayor número de vídeos

[http://www.youtube.com/watch?v=uIN7bz15Z-4, última consulta: 30 abril de 2010]; “Toni A. Martínez - Piso de 30 metros [http://www.youtube.com/watch?v=ry37onyuMZ0, última consulta: 30 abril de 2010]. 
referidos a su aspecto personal, principalmente debido al estilo gótico en la vestimenta que sus hijas mostraron en la visita a la Casa Blanca ${ }^{19}$.

\subsection{Los vídeos políticos en YouTube son de programas televisivos}

Un dato interesante en el análisis de los vídeos de YouTube es, por una parte, la autoría de los mismos y, por otra, el usuario de dicha plataforma que publica el material en la Red, ambas figuras no siempre coinciden en la misma. En esta línea, los datos del análisis (Tabla IV) muestran que la mayoría de los vídeos subidos a Internet pertenecen a programas de televisión (53). Unas cifras que vienen a reforzar el estudio realizado por Gallardo que ha demostrado la influencia de las cadenas de televisión en YouTube, dado el gran número de vídeos en la red que proceden de las cadenas generalistas. Según este investigador “[...] el peso de los contenidos procedentes de la televisión española es superior al resto de vídeos subidos a la red social de YouTube” (2010:170).

Tabla IV. Autor del vídeo y usuario que lo publica en YouTube

\begin{tabular}{|l|l|l|l|}
\hline & \multicolumn{3}{|c|}{ Publicado en la plataforma por: } \\
\hline Autor & Autor del vídeo & Otro usuario & Total \\
\hline Anónimo & 17 & 1 & 18 \\
\hline MdC & 20 & 33 & 53 \\
\hline Institucional & 8 & 1 & 9 \\
\hline Total & 45 & 35 & 80 \\
\hline
\end{tabular}

Fuente: Elaboración propia a partir de los vídeos de YouTube reproducidos el 6 de abril de 2010

La Sexta es la cadena de televisión autora de un mayor número de vídeos (10) publicados en Internet, concretamente de los siguientes programas: Buenafuente, El Intermedio, Sé lo que hicisteis, y en su mayoría los protagonistas son el líder de Partido Popular y Gaspar Llamazares ${ }^{20}$. Le sigue Televisión Española con 9 vídeos, en su mayor parte procedentes de dos

18 No se han computado aquellos vídeos en los que el objetivo está centrado en otros personajes.

19 Por ejemplo: "Hijas de Zapatero" [http://www.youtube.com/watch?v=LnVZdOtBDaU] cuyos comentarios al vídeo fueron eliminados.

20 Sirva de muestra: "Ortega Cano y Zapatero" de El Intermedio [http://www.youtube.com/watch?v=Y_Bkfxfvh7M, última consulta: 30 abril de 2010]; “SLQH: Patricia Conde llora de risa” de Sé lo que hicisteis [http://www.youtube.com/watch?v=2FOAu9zVhxk, última consulta: 30 abril de 2010], "Buenafuente 380 - Entrevista a Mariano Rajoy" de Buenafuente [http://www.youtube.com/watch? v=xo1ToUy5oZ8] o "Buenafuente 386-Bertovisión" [http://www.youtube.com/watch?v=pfvJGgANFIA, última consulta: 30 abril de 2010]. 
programas informativos espectacularizados -como son Tengo una pregunta para usted y 59 segundos- y principalmente con Llamazares como figura central ${ }^{21}$. En tercera posición se sitúa Libertad Digital Televisión con 7 vídeos procedentes de programas informativos, de tertulia o debate y casi en su totalidad (6) con Rosa Díez como protagonista. La cadena autonómica TV3 es la cuarta en cuanto a número de vídeos en YouTube, -provenientes fundamentalmente del programa televisivo de sátira política Polònia-, centrados, en gran medida, en el líder del Partido Popular²2.

Tras estas cadenas, otras como Cuatro, Telemadrid, Intereconomía, CNN+, 24 Horas de TVE, RAI, Caracol, Elmundo.es, La 2, Libertad Digital y Tele5 firman el resto de programas, principalmente de informativos o debates.

Además, de los 53 vídeos firmados por programas de televisión, otros 3 tienen autoría institucional -el propio partido político, el lobby político HazteOir.Org o el Congreso de los Diputados- y el resto, un total de 17 vídeos, corresponden a la iniciativa desarrollada por usuarios de Internet (Tabla V).

La mayoría de los vídeos, por tanto, subidos a YouTube no han sido creados ex profeso para la Red. No obstante, 22 de ellos sí lo fueron en su totalidad o parcialmente. Los usuarios editaron 13 de los 80 vídeos (Tabla V) tomando como base bien programas de televisión o imágenes no producidas originariamente por ellos -es el caso, por ejemplo, de uno de los vídeos sobre las hijas de Zapatero, en el que los usuarios realizaron un montaje a partir de fotografías de las protagonistas o publicadas en medios o Internet combinadas con audio, cuya autoría tampoco les corresponde ${ }^{23}-$. Únicamente 6 de los vídeos analizados sí han sido creados a propósito para internet -por ejemplo, los difundidos por el lobby político HazteOir.org, el vídeo cuyo tema son los mini-pisos o montajes animados elaborados íntegramente por los usuarios ${ }^{24}$.

${ }_{21}$ Véanse: "Las preguntas polémicas y las que se quedaron en el tintero" [http://www.youtube.com/watch?v=BsRv-IS7Hjw, última consulta: 30 abril de 2010] o "Tengo una pregunta para usted - Gaspar Llamazares" [http://www.youtube.com/watch?v=IdSIp3a5LII, última consulta: 30 abril de 2010].

22 Véanse: "Rajoy no sap dir "si" (polonia prog.37) [http://www.youtube.com/watch?v=KqqYIlqwgwc], TV3 - Polònia - El Rajoy es fa uns "Melendis" [http://www.youtube.com/watch?v=1K4nyy0BsZY] o Tengo aún más preguntas para usted, Sr. Rajoy Polònia [http://www.youtube.com/watch?v=KU5ox11kado].

23 Por ejemplo, el vídeo titulado "Hijas de Zapatero" [http://www.youtube.com/watch?v=LnVZdOtBDaU]

24 Véanse: "Toni A. Martínez - Piso de 30 metros” [http://www.youtube.com/watch?v=ry37onyuMZ0] o "Zapatero y Rajoy, Pasiones ocultas" [http://www.youtube.com/watch?v=xjpyC8vymqQ] Como detalle, éste es el único vídeo de los analizados que incorporar unos segundos de publicidad antes de su reproducción. 
Tabla V. Tipo de edición del vídeo por parte del usuario

\begin{tabular}{|c|c|c|c|c|c|c|}
\hline \multirow[b]{2}{*}{ ternet } & \multicolumn{6}{|c|}{ Tipo de edición de los vídeos } \\
\hline & audio & vídeo & Ambos & $\begin{array}{l}\text { Total vídeos } \\
\text { con edición }\end{array}$ & Sin edición & Total \\
\hline Sí & 6 & 1 & 6 & 13 & 9 & 22 \\
\hline No & 2 & 2 & 1 & 5 & 53 & 58 \\
\hline Total (80 vídeos) & 8 & 3 & 7 & 18 & 62 & 80 \\
\hline \multirow[t]{2}{*}{ Autor } & \multicolumn{6}{|c|}{ Tipo de edición de los vídeos } \\
\hline & audio & vídeo & Ambos & $\begin{array}{l}\text { Total vídeos } \\
\text { con edición }\end{array}$ & Sin edición & Total \\
\hline Anónimo & 6 & 1 & 6 & 13 & 5 & 18 \\
\hline MdC & 2 & 2 & 1 & 5 & 48 & 53 \\
\hline Institucional & 0 & 0 & 0 & 0 & 9 & 9 \\
\hline Total (80 vídeos) & 8 & 3 & 7 & 18 & 62 & 80 \\
\hline
\end{tabular}

Fuente: Elaboración propia a partir de los vídeos de YouTube reproducidos el 6 de abril de 2010

Cabe destacar que, aunque gran parte de los vídeos cuya autoría corresponde a un programa de televisión fueron publicados en YouTube por otro usuario, en general (48) son difundidos en Internet sin ningún tipo de retoque (ni de audio ni de imagen).

\subsection{Los vídeos publicados hace años siguen registrando comentarios}

Un aspecto que merece ser mencionado es la actualidad de los vídeos (Tabla VI): la mayoría de los vídeos que acumulan un mayor número de reproducciones, a fecha de 6 de abril de 2010, sobre José Luis Rodríguez Zapatero, Mariano Rajoy, Gaspar Llamazares y Rosa Díez han sido publicados en YouTube, mayoritariamente, en el año 2008 y en 2007. Un menor número lo fueron en los años 2009, 2006 y 2010, por ese orden. 
Tabla VI. Fecha de publicación en Internet del vídeo y del último comentario

\begin{tabular}{|l|l|l|l|l|}
\hline Año de publicación del vídeo & \multicolumn{2}{|l|}{ Último comentario de usuario recibido en los vídeos } & Total de vídeos \\
\hline & Última semana & Último mes & Último año o más & \\
\hline 2006 & 5 & 0 & 3 & 8 \\
\hline 2007 & 14 & 3 & 6 & 23 \\
\hline 2008 & 13 & 8 & 11 & 32 \\
\hline 2009 & 5 & 4 & 1 & 10 \\
\hline 2010 & 3 & 3 & 1 & 7 \\
\hline
\end{tabular}

Fuente: Elaboración propia a partir de los vídeos de YouTube reproducidos el 6 de abril de 2010

Estos datos resultarían insignificantes, al entender que a mayor tiempo publicado en Internet el vídeo, más posibilidades de ser reproducido un mayor número de veces, pero los resultados del análisis muestran (Tabla VI) que la mayoría de los comentarios a los vídeos publicados en 2008, 2007, 2006 y 2009 recibieron su último comentario entre la última semana de marzo y la primera de abril de 2010, justo antes de la recogida de datos para este análisis (e incluso algunos el mismo día). Los publicados en 2010 acumulan una mayoría de comentarios entre la última semana y el último mes.

Tabla VII. Número de comentarios de usuarios registrados en los vídeos

\begin{tabular}{|l|l|}
\hline Número de comentarios registrados & Número de vídeos con n comentarios \\
\hline Menos de 54 & 21 \\
\hline Entre 54 y 500 & 39 \\
\hline Entre 501 y 1000 & 8 \\
\hline Entre 1001 y 2000 & 4 \\
\hline Entre 2001 y 3000 & 3 \\
\hline Entre 3001 y 4000 & 0 \\
\hline Entre 4001 y 5000 & 2 \\
\hline Entre 5001 y 6000 & 0 \\
\hline Entre 6001 y 7000 & 1 \\
\hline
\end{tabular}




\begin{tabular}{|l|l|}
\hline Número de comentarios registrados & Número de vídeos con n comentarios \\
\hline Más de 7001 & 1 \\
\hline Total vídeos & 79 \\
\hline Total comentarios & 58.353 \\
\hline
\end{tabular}

Fuente: Elaboración propia a partir de los vídeos de YouTube reproducidos el 6 de abril de 2010

La participación de los usuarios en estos vídeos es relativamente alta si atendemos al número de comentarios por vídeo (tabla 7). La mayoría de los vídeos, un total de 39, acumulan, cada uno, entre 54 y 500 comentarios de usuarios (y la mayoría entre 100 y 200). La media es de 3,3 comentarios por 1.000 reproducciones de vídeo (teniendo en cuenta que el número total de reproducciones es de 17.534.713). De los 80 vídeos analizados en uno de ellos -referido a las hijas de Zapatero- fueron eliminados los comentarios registrados.

Tabla VIII. Perfil de usuarios por popularidad de vídeos más vistos en YouTube

\begin{tabular}{|c|c|c|}
\hline & Número de vídeos & Porcentaje \\
\hline \multicolumn{3}{|l|}{ Información por sexo } \\
\hline Hombre & 61 & $92,42 \%$ \\
\hline Mujer & 5 & $7,57 \%$ \\
\hline Total vídeos con datos & 66 & $82,5 \%$ \\
\hline Sin dato & 14 & $17,5 \%$ \\
\hline Total vídeos & 80 & $100 \%$ \\
\hline \multicolumn{3}{|c|}{ Información por grupos etarios } \\
\hline 35 a 44 años & 30 & $45,45 \%$ \\
\hline 45 a 54 años & 23 & $34,84 \%$ \\
\hline 13 a 17 años & 6 & $9,09 \%$ \\
\hline 25 a 34 años & 4 & $6,06 \%$ \\
\hline 18 a 24 años & 2 & $3,03 \%$ \\
\hline 55 a 64 años & 1 & $1,51 \%$ \\
\hline
\end{tabular}




\begin{tabular}{|l|l|l|}
\hline & Número de vídeos & Porcentaje \\
\hline Total vídeos con datos & 66 & $82,5 \%$ \\
\hline Sin dato & 14 & $17,5 \%$ \\
\hline Total vídeos & 80 & $100 \%$ \\
\hline
\end{tabular}

Fuente: Elaboración propia a partir de información facilitada por YouTube a 6 de abril de 2010

Por otro lado, la propia plataforma de YouTube facilita información relativa al sexo y franja de edad de los usuarios registrados que más reproducen y comentan sus vídeos (tabla 8). En esta línea, y atendiendo a los 80 vídeos analizados en este estudio, la mayoría de los vídeos más reproducidos de José Luis Rodríguez Zapatero, Mariano Rajoy, Gaspar Llamazares y Rosa Díez son populares entre hombres (92,42\%) con edades comprendidas entre los 35 y los 44 años, según datos de YouTube.

\section{Conclusiones}

Los resultados del análisis permiten confirmar la hipótesis planteada al inicio de esta investigación: entre los vídeos políticos examinados predomina el género del infoentretenimiento, tanto por la temática que abordan como por el estilo con el que la información audiovisual está elaborada.

En segundo término, los líderes políticos con mayor representación diaria en los medios de comunicación: José Luis Rodríguez Zapatero y Mariano Rajoy cuentan con más vídeos vinculados al infoentretenimiento que aquellos líderes que tienen menor exposición mediática: Gaspar Llamazares y Rosa Díez.

En tercer término, se aprecia que la mayor parte de los vídeos vinculados al infoentretenimiento que acumulan un mayor número de reproducciones en YouTube corresponden a programas de televisión, mayoritariamente La Sexta y Televisión Española, pero que son publicados en la referida plataforma por otros usuarios registrados, a título individual. Estos usuarios que difunden en YouTube programas de televisión, no editan dichos vídeos y se limitan a publicarlos tal cual han sido emitidos en las respectivas cadenas. En esta línea, los resultados muestran que estos vídeos corresponden, de forma mayoritaria, a series de infoshow -como por ejemplo: Buenafuente, La hora de José Mota, El Intermedio, Sé lo que hicisteis, Polònia, etc. - y, solo en reducidas ocasiones, a programas de información o debates televisivos. Este dato revelaría cierta pasividad en los usuarios de YouTube a la hora de generar productos audiovisuales propios de contenido político, concentrando su actividad en colgar vídeos de las televisiones generalistas contribuyendo así a difundir los productos convencionales. 
Aun así, aunque todavía de forma minoritaria, se aprecia que Internet está siendo un canal de expresión propia para los usuarios ya que se localizan vídeos creados expresamente para la Red. Usuarios que de forma creativa componen sus propios vídeos de contenido político y los difunden a través de YouTube.

En cuarto término, los datos revelan -y siempre referidos a los proporcionados por la propia plataforma de vídeos- que los hombres consumen en mayor medida este tipo de producto en YouTube que las mujeres, y sus edades están comprendidas entre los 35 y 54 años. Ellas únicamente superan a los varones en consumo de vídeos en 5 de los 80 analizados y en la franja de edad comprendida entre los 13 a 17 años.

En quinto término, se confirma que la personalización política se refleja en la selección de los usuarios a la hora de consumir vídeos en Internet. La mayoría de éstos tienen como protagonista al líder político y solo en casos aislados, al partido político. Además, esta personalización alcanza su máxima expresión en aquellos vídeos cuyo objetivo es el líder y su acción política, o incluso en su faceta personal, y no el partido que lo es en un número minoritario de vídeos.

Finalmente, tal y como se esperaba, los vídeos más reproducidos en YouTube sobre Zapatero y Rajoy tienen un sesgo claramente negativo, y únicamente en escasas ocasiones se interpreta con sesgo positivo. Sin embargo, en el caso de los líderes minoritarios aparecen en más ocasiones con un sesgo neutro.

YouTube, si atendemos a los vídeos más vistos de los cuatro candidatos, no se conforma como una plataforma audiovisual de debate político en torno a las cuestiones de estado sino como portal en el que satisfacer la curiosidad por imágenes sorprendentes, anécdotas curiosas y en el que visionar vídeos de humor que tienen como protagonistas a los líderes. Por lo tanto, los usuarios utilizan la plataforma como una fuente de entretenimiento y diversión y no como un medio de reflexión política o de profundización en los asuntos de actualidad.

\section{Referencias bibliográficas}

Arroyo, E. (2008): "El infotainment: de Caiga quien Caiga a Noche Hache", en P. Sangro y A. Salgado (eds.): El entretenimiento en TV: Guión y creación de formatos de humor en España. Barcelona: Laertes, pp. 173-192.

Bahry, L. (2001): “The new Arab media phenomenon: Qatar's Al-Jazeera”, Middle East Policy, 8, pp. 88-99.

Baum, M. A. (2002): "Sex, lies, and war: How soft news brings foreign policy to the inattentive public", American Political Science Review, 96, pp. 91-109.

- (2003a): “Soft news and political knowledge: Evidence of absence or absence of evidence?”, Political Communication, 20, pp. 173-190.

- (2003b): Soft news goes to war: Public opinion and American foreign policy in the new media age. Princeton; NJ: Princeton University Press. 
- (2005): “Talking the vote: Why presidential candidates hit the talk show circuit", American Journal of Political Science, 49, pp. 213-234.

Baum, M. A., Jamison, A. S. (2006) : “The Oprah effect: How soft news helps inattentive citizens vote consistently”, Journal of Politics, 68, pp. 946-959.

- (2007): "Soft news and foreign policy: How expanding the audience changes the policies", Japanese Journal of Political Science, 8, pp. 111-145.

Berrocal, S et. al. (2001): "La imagen de los partidos políticos en El Informal, CQC y Las Noticias del Guiñol en las elecciones legislativas de 2000”, ZER, 11, pp. 167- 185.

Berrocal, S., Abad. L., Cebrián, E., Pedreira, E., (2003): “El infoentretenimiento televisivo. Las elecciones legislativas de 2000", en S. Berrocal (coord.), Comunicación Política en Televisión y Nuevos Medios. Barcelona: Ariel, pp. 282-307.

Berrocal, S. y Campos, E. (2012): “El “infoentretenimiento” político en YouTube”, Estudios de Comunicación Política, ACOP.

- (2012): "El “infoentretenimiento" político en Internet. Un análisis de los videos más vistos en YouTube de José Luis Rodríguez Zapatero y Mariano Rajoy”, en Berrocal, S. y Campos, E.: La investigación en Periodismo Político en el entorno de los nuevos medios de comunicación. Madrid: Sociedad Española de Periodística.

Blumler, J.G. (ed.) (1992): Televisión and the Public Interest. London: Sage.

Blumler, J.G., Kavanagh, D. (1999): “The Third Age of Political Communication: Influences and Features”, Political Communication, 16, pp. 209-230.

Brants, K. (1998): “Who's afraid of infotainment”, European Journal of Communication, 13, pp. 315-335.

Brants, K., Neijens, P. (1998): “The infotainment of politics”, Political Communication, 15, pp. 149-164.

Campos, E. (2011): La ciberdemocracia en el Congreso de los Diputados (2004-2008). Madrid: Congreso de los Diputados.

Carpio, J.A. (2009): El humor en los medios de comunicación. Estudio de Los Guiñoles y sus efectos en las opiniones políticas, tesis doctoral inédita, Universidad Pontificia de Salamanca.

Delli Carpini, M.W., Williams, B.A. (2001): “Let Us Infotain You: Politics in the New Media Age”, en W. Lance Bennett, R. M. Entman: Mediated Politics: Communication in the Future of Democracy. Cambridge, UK; New York : Cambridge University Press, pp. 160-181.

Díez Arias, R. (2007): Periodismo en Televisión. Entre el espectáculo y el testimonio de la realidad. Barcelona: Bosch.

Ferré, C. i Gayà, C. (2009): Infoentreteniment i percepción ciutadana de la política: el cas de Polònia. Barcelona: Consell de l'Audiovisual de Catalunya.

García Avilés, J.A. (2007): “El infoentretenimiento en los informativos líderes de audiencia en la Unión Europea”, Anàlisi, vol. 35, pp. 47-63. 
Hanson, G.L., Haridaski, P.M., Sharma, R. (2011): "Differing uses of YouTube during the 2008 U.S. Presidential Primary Election", Electronic News, 5: 1.

Hollander, B. A. (2005): "Late-night learning: Do entertainment programs increase political campaign knowledge for young viewers?", Journal of Broadcasting and Electronic Media, 49, pp. 402-415.

Holtz-Bacha, C., Norris, P. (2001): “To entertain, inform and educate: still the role of Public Television”, Political Communication, 18, pp. 123-140.

Lynch, M. (2004a): “America and the Arab media environment”, en W. A. Rugh (Ed.), Engaging the Arab and Islamic worlds through public diplomacy. Washington, DC: Public Diplomacy Council, pp. 90-108.

Lynch, M. (2004b): "Shattering the politics of silence: Satellite television talk shows and the transformation of Arab political culture", Arab Reform Bulletin, 2, pp. 3-4.

Martínez Nicolás, M. (2007): “Agitación en el campo. Nueve ideas para la investigación sobre comunicación política en España”. Política y sociedad, 44 (2), pp. 209-227.

Moreno del Río, C. (2010): “El 'Zejas’ y la 'niña de Rajoy'. Análisis sobre el papel del humor en las elecciones generales españolas de 2008”, Revista Española de Ciencia Política, no 22, pp. 71-95.

Moy, P., Xenos, M. A., Hess, V. K. (2006): “Priming effects of late-night comedy”, International Journal of Public Opinion Research, 18, pp. 198-210.

Patterson, T. E. (2000): Doing well and doing good: How soft news and critical journalism are shrinking the news audience and weakening democracy — and what news outlets can do about it. Cambridge: MA: Harvard University, John F. Kennedy School of Government.

Prado, E. (2003): “La espectacularización de la realidad”, Anuario de la televisión. Madrid: GECA.

Prior, M. (2003): "Any good news in soft news? The impact of soft news preference on political knowledge”, Political Communication, 20, pp. 149-171.

Prior, M. (2005): "News vs. entertainment: How increasing media choice widens gaps in political knowledge and turnout", American Journal of Political Science, 49, pp. 577-592.

Prior, M. (2007): Post-broadcast democracy: How media choice increases inequality in political involvement and polarizes elections. Cambridge, England: Cambridge University Press.

Sampedro, V. (2000): Opinión pública y democracia deliberativa. Medios, sondeos y urnas. Madrid: Istmo.

Shirk, S. L. (2007): “Changing media, changing foreign policy in China”, Japanese Journal of Political Science, 8, pp. 43-70.

Schudson, (1999): “You've Got Mail: A Few Observations on Hope”, Social Research: An International Quarterly, vol. 66, n², pp. 625-628. 
Taniguchi, M. (2007): “Changing media, changing politics in Japan”, Japanese Journal of Political Science, 8, pp. 147-166.

- (2011): “The electoral consequences of candidate appearances on soft news programs”, Political Communication, 28: 1, pp. 67-86.

Towner, T.L., Dulio, A. D. (2011): “An experiment of campaign effects during the YouTube election”, New Media \& Society, vol. 13, no. 4, pp. 626-644.

Tyron, Ch. (2008): “Pop Politics: Online Parody Videos, Intertextuality, and Political Participation”, Popular Communication: The International Journal of Media and Culture, vol. 6, 4, pp. 209-213.

Valhondo, J.L. (2011): Sátira televisiva y democracia en España. La popularización de la información política a través de la sátira. Barcelona: Editorial UOC. 